International Journal of Electrical and Power Engineering 4 (3): 182-192, 2010

ISSN: 1990-7958

(C) Medwell Journals, 2010

\title{
Design of a Robust Multivariable Controller for an AC-VSC-HVDC System
}

\author{
${ }^{1}$ P.K. Dash, ${ }^{1}$ R.K. Mallick and ${ }^{2}$ A.K. Moharana \\ ${ }^{1}$ Siksha ' $\mathrm{O}$ ' Anusandhan University, Bhubaneswar, India \\ ${ }^{2}$ Department of Electrical and Computer Engineering, UWO, London, Ontario, Canada
}

\begin{abstract}
In this study, a Voltage Source Converter based High Voltage Direct Current (VSC-HVDC) transmission link is considered for the development of a multivariable robust controller to stabilize the AC-VSCHVDC power system. To maintain the dc voltage and control the active and reactive power at the converter and inverter stations simultaneously a robust $\mathrm{H}_{\infty}$ control design methodology is adopted here. For designing the controller output feedback quantities like the converter side dc voltage and reactive power and the inverter side active and reactive power are obtained and used to satisfy an and $\mathrm{H}_{\infty}$ norm of the closed loop transfer function matrix. The proposed controller is evaluated for different power system operating conditions like the threephase short-circuits on the converter and inverter buses, short-circuit on the dc line, loading changes, etc. and its performance show better results than the earlier used PI controllers in respect of the reduction of overshoots, faster settling times and improved damping for the electromechanical oscillations of the generators.
\end{abstract}

Key words: VSC-HVDC system, output feedback, $\mathrm{H}_{\infty}$ controller, generators, dc voltage, Canada

\section{INTRODUCTION}

Voltage source converter based HVDC using IGBTs and Pulse Width Modulation (PWM) techniques have been developed by companies like $\mathrm{ABB}$ and Siemens and there are a number of installations now in operation world wide (Andersen et al, 2002; Jowder and Ooi, 2004; Asplund, 2000) for applications in power generation, transmission and distribution. In a VSC-HVDC system connecting two AC networks, the control of the dc link voltage connecting the two converters and the real and reactive power outputs are of primary interest for control engineers.

In contrast to the conventional thyristor-based HVDC system, the VSC-HVDC system has certain distinct advantages like the instantaneous switching of IGBT valves; absence of commutation failure and independent control of real and reactive power flows on both sides of the converters; the need of a small AC filter for high frequency signals from the PWM. recent times, the VSC-HVDC transmission systems are being considered actively for transporting power from offshore wind power generating systems to the main grid and in addition they are not affected by power quality problems in the connecting $\mathrm{AC}$ networks. Besides they offer great advantages in comparison to the FACTS devices in providing significant improvements in system dynamic performance.

Although, there are several advantages of VSCHVDC transmission, the most important requirement involves the design of a suitable controller for the rectifier and inverter systems to provide improved dynamic performance. The various control inputs at the rectifier and inverter stations comprise the PWM modulation index and angle at each of the two converter stations. The VSCHVDC system is essentially a multi-input and multi-output nonlinear system due to the strong interaction between the several input variables and hence its controller design becomes more complex.

For converter control, linear PI control scheme has been adopted by several researchers without taking into account the various disturbances and interferences that exist in VSC control systems such as the imprecise mathematical models, the measurement errors, input disturbances stochastic fluctuations of load and DC ripples and PWM triggering technique for the converter, etc. Further, the PI-controllers are very often designed by trial and error and can not provide stability over a wide range of operating conditions.

Among the nonlinear controllers feedback linearization has been widely used (Zhang and $\mathrm{Xu}, 2001$; Zhang et al., 2002; Durrant et al., 2004; Liang et al., 2005; Ruan et al., 2007a, b) to precisely cancel VSC model nonlinearities. The control schemes in these studys, however do not consider the generator speed variation which may destabilize the system when it varies over a wide margin. Therefore, a robust controller design is required to become insensitive to interferences, model uncertainties and load fluctuations, short-circuits, etc., over a wide ranging of operating conditions. Robust

Corresponding Author: P.K. Dash, Siksha 'O' Anusandhan University, Bhubaneswar, India 
control techniques have been applied to power systems since late 1980s. Some of those efforts have been contributed to design of robust controllers for FACTS devices using $\mathrm{H}_{\infty}$ concept such as mixed sensitivity (Pal, 2002; Lignon et al., 2006), $\mu$ synthesis (Lignon et al., 2006). In earlier studies for the design of robust controllers, many classical control objectives such as disturbance attenuation, robust stabilization of uncertain systems are expressed in terms of $\mathrm{H}_{\infty}$ norms and use LMI concepts like mixed sensitivity control (Pal, 2002) $\mu$ synthesis (Lignon et al., 2006).

In all the $\mathrm{H}_{\infty}$ controller designs, a single norm is used which normally will not be able to provide stability over a wide range of operating conditions in AC-VSC-HVDC power system. Hence, for providing a more accurate closed loop behavior, it is desirable to mix different objectives in the time and frequency domain and for this purpose the proposed controller uses output feedback. Further to improve the damping performance of the generators in addition to robust performance of the converters, an auxiliary $\mathrm{H} \infty$-damping controller is used.

\section{MATERIALS AND METHODS}

Modeling of the decoupled vsc-hvdc system: Figure 1a shows a two-area decoupled AC-VSC-HVDC system. A short double-circuit transmission line connects the generator and the converter station. The VSC-HVDC is connecting two asynchronous systems. One system is operating with $50 \mathrm{~Hz}$ where as the other is with $60 \mathrm{~Hz}$. The reactances of the short lines are $\mathrm{x}_{\mathrm{t} 11}$ and $\mathrm{x}_{\mathrm{t} 12}$ in the area-1 and $x_{t 21}$ and $x_{t 22}$ in area-2. The impedances of the converter and the inverter are $\mathrm{r}_{\mathrm{r}}+\mathrm{j} \mathrm{x}_{\mathrm{r}}$ and $\mathrm{r}_{\mathrm{j}}+\mathrm{j} \mathrm{x}_{\mathrm{p}}$ respectively. The two VSC stations are connected through a DC transmission line of resistance $r_{d c} . P_{L 1}, Q_{L 1}$ and $P_{L 2}, Q_{L} 2$ are the loads in the area- 1 and area- 2 , respectively. The DC link capacitor $\mathrm{C}_{\mathrm{dc}}$ used at each station maintains the constant DC voltage.

The generating systems tested are of third order and well known. The set of equations that describes the synchronous generators are given in Appendix. The DC link equations are obtained as Rectifier:

$$
\begin{gathered}
\frac{\mathrm{di}_{\mathrm{rD}}}{\mathrm{dt}}=\frac{-\mathrm{r}_{\mathrm{r}}}{1_{\mathrm{r}}} \mathrm{i}_{\mathrm{rD}}+\omega_{1} \mathrm{i}_{\mathrm{rQ}}+\frac{\left(v_{1 \mathrm{D}}-v_{\mathrm{rD}}\right)}{1_{\mathrm{r}}} \\
\frac{\mathrm{di} \mathrm{rQ}}{\mathrm{dt}}=\frac{-\mathrm{r}_{\mathrm{r}}}{1_{\mathrm{r}}} \mathrm{i}_{\mathrm{rQ}}-\omega_{1} i_{\mathrm{rD}}+\frac{\left(v_{1 \mathrm{Q}}-v_{\mathrm{rQ}}\right)}{1_{\mathrm{r}}} \\
\frac{\mathrm{dv} \mathrm{dc1}}{\mathrm{dt}}=\frac{\mathrm{P}_{\mathrm{dc} 1}}{\mathrm{C}_{\mathrm{dc}}}-v_{\mathrm{dc} 1}\left(\frac{1}{\mathrm{C}_{\mathrm{dc}} \mathrm{r}_{\mathrm{dc}}}\right)+v_{\mathrm{dc} 2}\left(\frac{1}{\mathrm{C}_{\mathrm{dc}} \mathrm{r}_{\mathrm{dc}}}\right)
\end{gathered}
$$

Inverter:

$$
\begin{aligned}
& \frac{\mathrm{di}_{\mathrm{iD}}}{\mathrm{dt}}=\frac{-\mathrm{r}_{\mathrm{i}}}{1_{\mathrm{i}}} \mathrm{i}_{\mathrm{iD}}+\omega_{2} \mathrm{i}_{\mathrm{iQ}}+\frac{\left(-v_{2 \mathrm{D}}+v_{\mathrm{iD}}\right)}{1_{\mathrm{i}}} \\
& \frac{\mathrm{di}_{\mathrm{iQ}}}{\mathrm{dt}}=\frac{-\mathrm{r}_{\mathrm{i}}}{1_{\mathrm{i}}} \mathrm{i}_{\mathrm{iQ}}-\omega_{2} \mathrm{i}_{\mathrm{iD}}+\frac{\left(-v_{2 \mathrm{Q}}+v_{\mathrm{iQ}}\right)}{1_{\mathrm{i}}}
\end{aligned}
$$

Where as:

$$
\begin{aligned}
& \mathrm{Pe}_{1}=v_{1 \mathrm{D}} \cdot \mathrm{i}_{1 \mathrm{D}}+v_{1 \mathrm{Q}} \cdot \mathrm{i}_{1 \mathrm{Q}} \mathrm{Pe}_{2}=v_{2 \mathrm{D}} \cdot \mathrm{i}_{2 \mathrm{D}}+v_{2 \mathrm{Q}} \cdot \mathrm{i}_{2 \mathrm{Q}} \\
& \mathrm{P}_{\mathrm{dc} 1}=v_{1 \mathrm{D}} \mathrm{i}_{\mathrm{rD}}+v_{1 \mathrm{Q}} \mathrm{i}_{\mathrm{rQ}}-\left(\mathrm{i}_{\mathrm{rD}}^{2}+\mathrm{i}_{\mathrm{rQ}}^{2}\right) \mathrm{r}_{\mathrm{r}}
\end{aligned}
$$

$\mathrm{i}_{\mathrm{rD}}, \mathrm{i}_{\mathrm{rQ}}, \mathrm{i}_{\mathrm{iD}}$ and $\mathrm{i}_{\mathrm{iQ}}$ are the converter and inverter currents in the dq frame. $V_{\mathrm{rD}}, \mathrm{V}_{1 \mathrm{Q}}, \mathrm{V}_{\mathrm{rD}}$, and $\mathrm{V}_{\mathrm{iQ}}$ de side voltage of the converter and inverter. $V_{1 \mathrm{D}}, \mathrm{V}_{1 \mathrm{Q}}, \mathrm{V}_{2 \mathrm{D}}$ and $\mathrm{V}_{2 \mathrm{Q}}$ are the ac voltage of bus one and bus two in dq frame. $V_{\mathrm{dc} 1}$ and $\mathrm{V}_{\mathrm{dc} 2}$ are the dc voltages at the converter and inverter station.

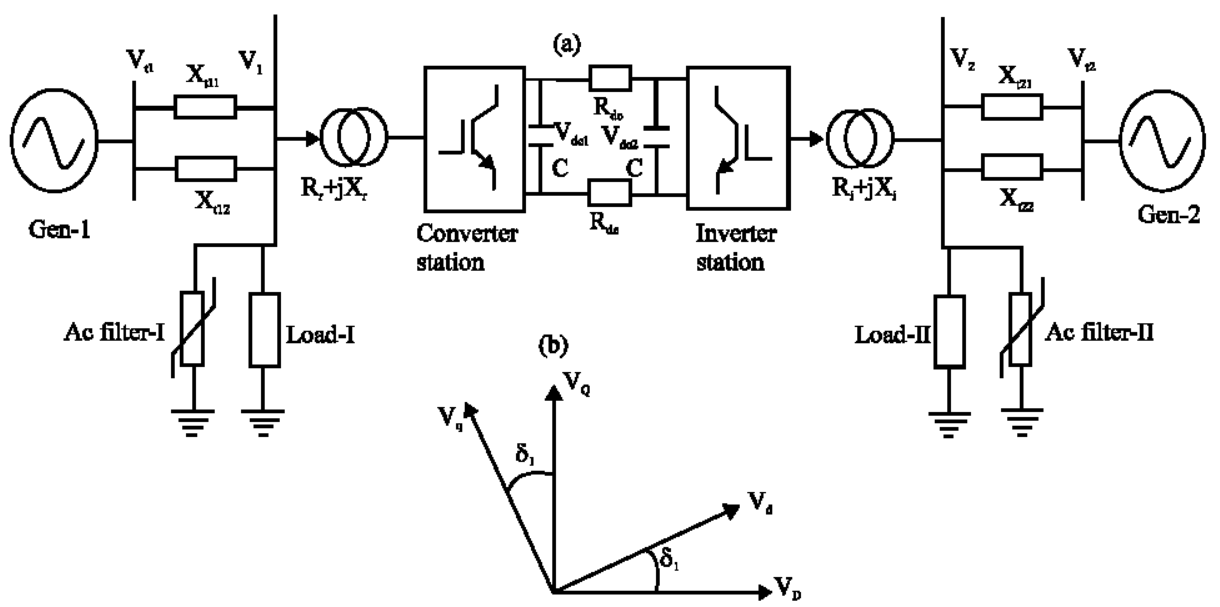

Fig. 1: VSC HVDC system; a) two area decoupled VSC-HVDC; b) transformation of phasors, DQ is for local and dq is for machine frame 
Robust controller formulation for VSC-HVDC: For the purpose of the control of the converter and inverter station here, a 5 th order model is used. The converter and inverter equations are solved in the local frame of the converter shown in Fig. 2 which enables the exact estimation of power flow to the converter. The dynamic equations used for the simulation and control calculation are as follows At the rectifier side, the q-axis voltage is set to be in phase with bus voltage $V_{1}$ and correspondingly the q-axis voltage is set to be in phase with $V_{2}$ on the inverter side. This produces a simplification of the form $V_{1 Q}=0, V_{1 Q}=V_{11}$ at the rectifier side and $V_{2 D}=0, V_{2 Q}=V_{2}$ at the inverter side. Therefore, the expressions for the active and reactive powers on the rectifier and inverter sides become:

and

$$
\mathrm{Pe}_{1}=\mathrm{V}_{1} \cdot \mathrm{I}_{1 \mathrm{Q}} \mathrm{Pe}_{2}=\mathrm{V}_{2} \cdot \mathrm{I}_{2 \mathrm{Q}}
$$

$$
\mathrm{Qe}_{1}=\mathrm{V}_{1} \cdot \mathrm{I}_{1 \mathrm{D}} \quad \mathrm{Qe}_{2}=\mathrm{V}_{2} \cdot \mathrm{I}_{2 \mathrm{D}}
$$

Further at the rectifier side, there are two controlled variables: the reactive power $Q_{1}$ and DC-bus voltage $V_{\text {dc1 }}$ and the corresponding control variables at the inverter side are the active power $\mathrm{P}_{\mathrm{e} 2}$ and reactive power $\mathrm{Q}_{\mathrm{e} 2}$. The dynamic equations used for the simulation and control calculation are as follows:

$$
\begin{gathered}
\mathrm{p} . \mathrm{i}_{\mathrm{rD}}=\frac{-\mathrm{r}_{\mathrm{r}}}{1_{\mathrm{r}}} \mathrm{i}_{\mathrm{rD}}+\omega_{1} \mathrm{i}_{\mathrm{rQ}}+\frac{\left(-v_{\mathrm{rD}}\right)}{1_{\mathrm{r}}} \\
\mathrm{p} . \mathrm{i}_{\mathrm{rQ}}=\frac{-\mathrm{r}_{\mathrm{r}}}{1_{\mathrm{r}}} \mathrm{i}_{\mathrm{rQ}}-\omega_{1} \mathrm{i}_{\mathrm{rD}}+\frac{\left(v_{1}-v_{\mathrm{rQ}}\right)}{1_{\mathrm{r}}} \\
\mathrm{p} . v_{\mathrm{dc} 1}=\frac{\mathrm{P}_{\mathrm{dc} 1}}{\mathrm{C}_{\mathrm{dc}}}-v_{\mathrm{dc} 1}\left(\frac{1}{\mathrm{C}_{\mathrm{dc}} \mathrm{r}_{\mathrm{dc}}}\right)+v_{\mathrm{dc} 2}\left(\frac{1}{\mathrm{C}_{\mathrm{dc}} \mathrm{r}_{\mathrm{dc}}}\right) \\
\mathrm{p} . \mathrm{i}_{\mathrm{iD}}=\frac{-\mathrm{r}_{\mathrm{i}}}{1_{\mathrm{i}}} \mathrm{i}_{\mathrm{iD}}+\omega_{2} \mathrm{i}_{\mathrm{iQ}}+\frac{\left(v_{\mathrm{iD}}\right)}{1_{\mathrm{i}}} \\
\text { p. } \mathrm{i}_{\mathrm{iQ}}=\frac{-\mathrm{r}_{\mathrm{i}}}{1_{\mathrm{i}}} 1_{\mathrm{iQ}}-\omega_{2} \mathrm{i}_{\mathrm{iD}}+\frac{\left(-v_{2}+v_{\mathrm{iQ}}\right)}{1_{\mathrm{i}}}
\end{gathered}
$$

In the model, the differential equation of the DC voltage $\mathrm{V}_{\mathrm{dc} 2}$ is not taken as it is not the controlled quantity and is solely determined from the rectifier side control. While designing the converter any change in the angular speed of the machine is treated as the disturbance input to the converter and inverter. So the main objective of the $\mathrm{H}_{\infty}$ controller is to reject the disturbance and provide

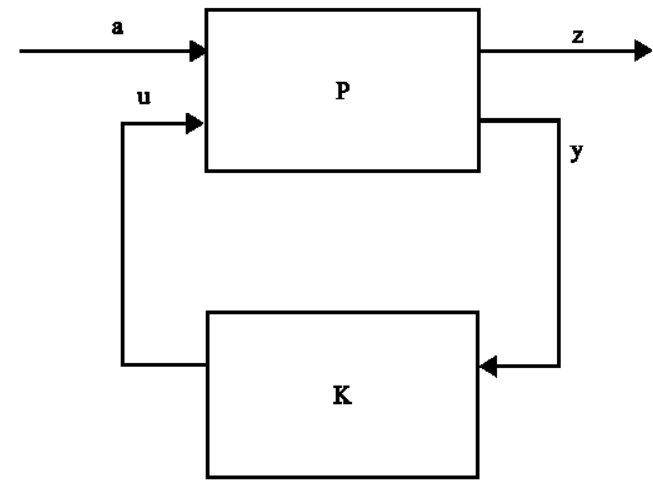

Fig. 2: Configuration of output feedback $\mathrm{H}_{\infty}$ controller

robust control of active and reactive power to the DC voltage. Since the equations are in the non-linear form, those can be linearized by perturbation and the small signal model is given by:

$$
\begin{aligned}
& \dot{x}(t)=A x(t)+B_{1} d(t)+B_{2} u(t) \\
& z(t)=C_{1} x(t)+D_{11} d(t)+D_{12} u(t) \\
& y(t)=C_{2} x(t)+D_{21} d(t)+D_{22} u(t)
\end{aligned}
$$

Where:

$\mathrm{x}(\mathrm{t})=$ The state variables

$\mathrm{d}(\mathrm{t})=$ The disturbance inputs

$\mathrm{u}(\mathrm{t})=$ The control inputs

$\mathrm{Z}(\mathrm{t})=$ The observed state

$\mathrm{y}(\mathrm{t})=$ The output state

The VSC-HVDC system states and control are obtained as:

$$
\begin{aligned}
& \mathrm{x}_{\mathrm{R}}=\left[\begin{array}{lll}
\mathrm{i}_{\mathrm{rD}} & \mathrm{i}_{\mathrm{rQ}} & \mathrm{v}_{\mathrm{dcl}}
\end{array}\right]^{\mathrm{T}} \mathrm{x}_{\mathrm{I}}=\left[\begin{array}{ll}
\mathrm{i}_{\mathrm{iD}} & \mathrm{i}_{\mathrm{iQ}}
\end{array}\right]^{\mathrm{T}} \\
& \mathrm{d}_{\mathrm{R}}=\left[\begin{array}{lll}
\mathrm{d}_{1} & \mathrm{~d}_{2} & \mathrm{~d}_{3}
\end{array}\right]^{\mathrm{T}} \mathrm{d}_{\mathrm{I}}=\left[\begin{array}{ll}
\mathrm{d}_{1} & \mathrm{~d}_{2}
\end{array}\right]^{\mathrm{T}}
\end{aligned}
$$

where, $\mathrm{d}$ represents the disturbances.

$$
\begin{gathered}
\mathrm{u}_{\mathrm{R}}=\left[\begin{array}{l}
\mathrm{u}_{1} \\
\mathrm{u}_{2}
\end{array}\right]=\left[\begin{array}{c}
-v_{\mathrm{rD}} \\
v_{1}-v_{\mathrm{rQ}}
\end{array}\right] \mathrm{y}_{\mathrm{R}}=\left[\begin{array}{c}
\mathrm{i}_{\mathrm{rD}} \\
v_{\mathrm{dcl} 1}
\end{array}\right] \\
\mathrm{u}_{\mathrm{I}}=\left[\begin{array}{c}
\mathrm{u}_{3} \\
\mathrm{u}_{4}
\end{array}\right]=\left[\begin{array}{c}
v_{\mathrm{iD}} \\
v_{\mathrm{iQ}}-v_{2}
\end{array}\right] \mathrm{y}_{\mathrm{I}}=\left[\begin{array}{c}
\mathrm{i}_{\mathrm{iD}} \\
\mathrm{i}_{\mathrm{iQ}}
\end{array}\right] \\
\mathrm{u}_{1}=-\mathrm{m}_{\mathrm{r}} v_{\mathrm{dcl}} \sin \left(\alpha_{\mathrm{r}}\right) \mathrm{u}_{2}=v_{1}-\mathrm{m}_{\mathrm{r}} v_{\mathrm{dcl}} \cos \left(\alpha_{\mathrm{r}}\right) \\
\mathrm{m}_{\mathrm{r}}=\frac{\sqrt{\left(-\mathrm{u}_{1}\right)^{2}+\left(v_{1}-\mathrm{u}_{2}\right)^{2}}}{v_{\mathrm{dcl}}} \alpha_{\mathrm{r}}=\tan ^{-1}\left(\frac{-\mathrm{u}_{1}}{v_{1}-\mathrm{u}_{2}}\right) \\
\mathrm{u}_{3}=\mathrm{m}_{\mathrm{i}} v_{\mathrm{dc} 2} \sin \left(\alpha_{\mathrm{i}}\right) \mathrm{u}_{4}=\mathrm{m}_{\mathrm{i}} v_{\mathrm{dcc}} \cos \left(\alpha_{\mathrm{i}}\right)-v_{2}
\end{gathered}
$$


Int. J. Elec. Power Eng., 4 (3): 182-192, 2010

$$
\mathrm{m}_{\mathrm{i}}=\frac{\sqrt{\left(\mathrm{u}_{3}\right)^{2}+\left(\mathrm{u}_{4}-v_{2}\right)^{2}}}{v_{\mathrm{dc} 2}} \alpha_{\mathrm{i}}=\tan ^{-1}\left(\frac{\mathrm{u}_{3}}{\mathrm{u}_{4}-v_{2}}\right)
$$

The system matrices shown in Eq. 11 are obtained from the small signal analysis as:

$$
A_{R}=\left[\begin{array}{ccc}
-\frac{r_{r}}{1_{r}} & \omega_{10} & 0 \\
-\omega_{10} & -\frac{r_{r}}{1_{r}} & 0 \\
\frac{-u_{10}}{v_{d c 1} \cdot C_{d c}} & \frac{v_{1}-u_{20}}{v_{d c 1} \cdot C_{d c}} & \frac{\left(-u_{10}\right) i_{r D}+\left(v_{1}-u_{20}\right) \cdot i_{\mathrm{rQ}}}{v_{d c 1}^{2} \cdot C_{d c}}-\left(\frac{1}{r_{d c} \cdot C_{d c}}\right)
\end{array}\right]
$$

$$
B_{R 1}=\left[\begin{array}{lll}
1 & 0 & 0 \\
0 & 1 & 0 \\
0 & 0 & 1
\end{array}\right] \text { and } B_{R 2}=\left[\begin{array}{cc}
\frac{1}{1_{r}} & 0 \\
0 & \frac{1}{1_{r}} \\
0 & 0
\end{array}\right]
$$

Observation and out put state matrices are as chosen as follows:

$$
\begin{aligned}
& C_{R 11}=\left[\begin{array}{lll}
1 & 0 & 0 \\
0 & 0 & 0 \\
0 & 0 & 1
\end{array}\right], C_{R 21}=\left[\begin{array}{lll}
1 & 0 & 0 \\
0 & 0 & 1
\end{array}\right] \\
& D_{R 11}=\left[\begin{array}{lll}
1 & 0 & 0 \\
0 & 1 & 0 \\
0 & 0 & 1
\end{array}\right], D_{R 12}=\left[\begin{array}{ll}
0 & 0 \\
0 & 0 \\
0 & 0
\end{array}\right] \\
& D_{R 21}=\left[\begin{array}{lll}
1 & 0 & 0 \\
0 & 0 & 1
\end{array}\right], D_{R 22}=\left[\begin{array}{ll}
0 & 0 \\
0 & 0
\end{array}\right] \\
& A_{I}=\left[\begin{array}{cc}
-\frac{r_{1}}{1_{i}} & \omega_{20} \\
-\omega_{20} & -\frac{r_{i}}{1_{i}}
\end{array}\right] B_{I 1}=\left[\begin{array}{ll}
1 & 0 \\
0 & 1
\end{array}\right] B_{12}=\left[\begin{array}{cc}
\frac{1}{1_{i}} & 0 \\
0 & \frac{1}{1_{i}}
\end{array}\right]
\end{aligned}
$$

Observed and out put state matrices are as chosen as follows:

$$
\mathrm{C}_{111}=\left[\begin{array}{ll}
1 & 0 \\
0 & 1
\end{array}\right], \mathrm{C}_{121}=\left[\begin{array}{ll}
1 & 0 \\
0 & 1
\end{array}\right]
$$

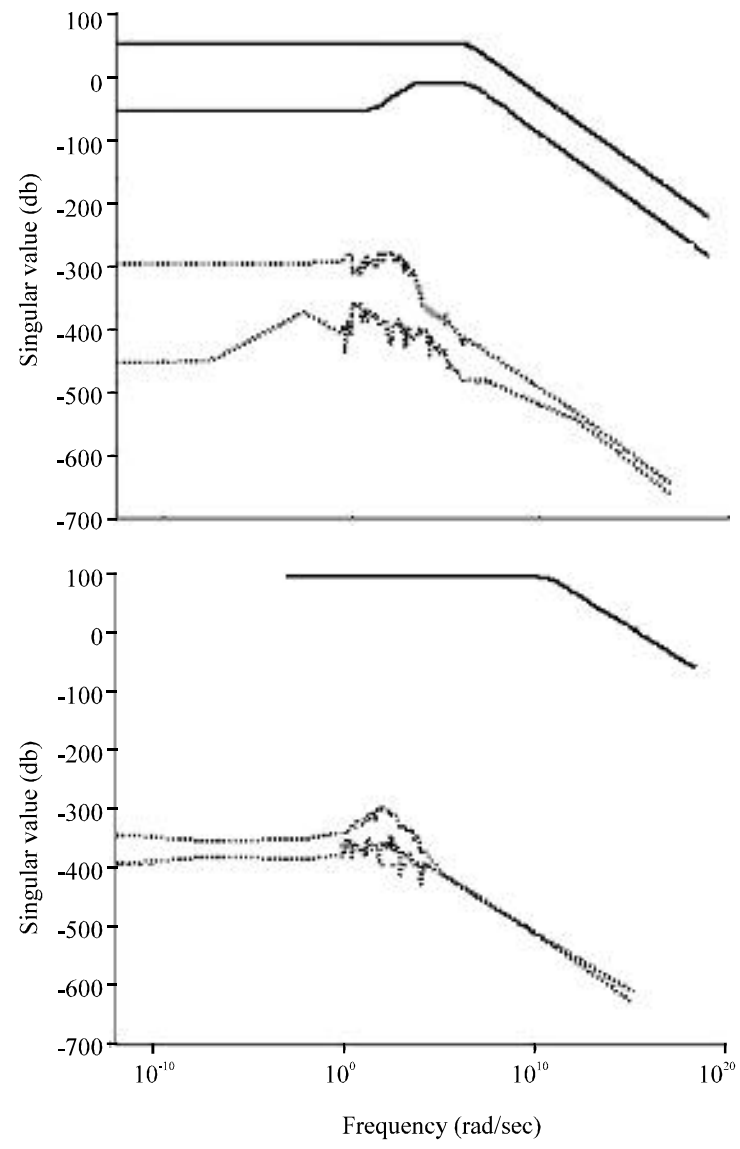

Fig. 3: Singular value of a) converter and b) inverter

$$
\begin{aligned}
& D_{111}=\left[\begin{array}{ll}
1 & 0 \\
0 & 1
\end{array}\right], D_{121}=\left[\begin{array}{ll}
1 & 0 \\
0 & 1
\end{array}\right] ; \\
& D_{112}=\left[\begin{array}{ll}
0 & 0 \\
0 & 0
\end{array}\right], D_{122}=\left[\begin{array}{ll}
0 & 0 \\
0 & 0
\end{array}\right] ;
\end{aligned}
$$

Robust multivariable control design for VSC-HVDC system: Due to uncertain load and frequency fluctuations of the power network, ripples in the DC side of converters and PWM triggering techniques used in the converters, the primary objective in designing a robust controller is to minimize the impact of these disturbances on the ACVSC-HVDC system.

The output disturbance rejection problem is formulated using the $\mathrm{H}_{\infty}$ control theory after transforming the domain linearized in Eq. 11 to corresponding equations in the frequency domain.

Figure 3 shows the $\mathrm{H}_{\infty}$ configuration in block diagram form showing the input output and observations. The generalized equation of the transformation can be written as: 
Where:

$$
P_{i j}=C_{i}(s I-A)^{-1} B_{j}+D_{i j}
$$

$$
P(s)=\left(\begin{array}{ll}
D_{11} & D_{12} \\
D_{21} & D_{22}
\end{array}\right)+\left(\begin{array}{l}
C_{1} \\
C_{2}
\end{array}\right)(s I-A)^{-1}\left(B_{1} B_{2}\right)
$$

and

$$
\mathrm{P}(\mathrm{s})=\left(\begin{array}{ll}
\mathrm{P}_{11} & \mathrm{P}_{12} \\
\mathrm{P}_{21} & \mathrm{P}_{22}
\end{array}\right)
$$

Defining the output feedback controller K (s) by:

$$
\mathrm{u}=\mathrm{K}(\mathrm{s}) . \mathrm{Y}
$$

The closed loop transfer function matrix can be written as:

$$
\mathrm{T}_{z \mathrm{~d}}(\mathrm{~s})=\mathrm{P}_{11}+\mathrm{P}_{12} \mathrm{~K}\left(1-\mathrm{P}_{11} \mathrm{~K}\right)^{-1} \mathrm{P}_{21}
$$

The controller gain $\mathrm{K}$ is obtained by satisfying the such that $\mathrm{H}_{\infty}$ norm that is $\left\|\mathrm{T}_{z \mathrm{~d}}(\mathrm{~s})\right\|_{\infty}<\gamma$. Where $\gamma$ is a positive number with $\gamma_{\max }=1$.

Figure 3 shows the configuration of the VSC-HVDC plant $\mathrm{P}$ and the transfer matrix $\mathrm{P}_{11}$ describes about the uncertainties and performance specification, $\mathrm{P}_{12}$ gives the information about the shaping of the controller, $\mathrm{P}_{21}$ details the effects of the disturbances and uncertainties on the measured signal and $\mathrm{P}_{22}$ gives the information about the impact of inputs on the measured outputs. The output feedback control system gain matrix $\mathrm{K}$ is obtained solving the matrix Riccati equations to yield two semi definite matrices $\mathrm{X}$ and $\mathrm{Y}$ in the form given:

$$
\begin{aligned}
& X A+A^{T} X-X\left(B_{2} B_{2}^{T}-\frac{1}{\gamma^{2}} B_{1} B_{1}^{T}\right) X+C_{1} C_{1}^{T}=0 \\
& Y A+A^{T} Y-Y\left(C_{2}^{T} C_{2}-\frac{1}{\gamma^{2}} C_{1}^{T} C_{1}\right) Y+B_{1} B_{1}^{T}=0
\end{aligned}
$$

and $\mathrm{p}(\mathrm{XY})<\gamma^{2}, \gamma$ is a positive number $<1$. The controller gain matrix $\mathrm{K}$ is calculated as follows:

$$
\mathrm{K}=\mathrm{F}(\mathrm{sI}-\hat{\mathrm{A}})^{-1} \mathrm{ZL}
$$

Where:

$$
\begin{gathered}
\mathrm{F}=-\mathrm{B}_{2}^{\mathrm{T}} \mathrm{X} \\
\mathrm{L}=-\mathrm{YC}_{2}^{\mathrm{T}}
\end{gathered}
$$

Where:

$$
\hat{\mathrm{A}}=\mathrm{A}+\frac{1}{\gamma^{2}} \mathrm{~B}_{1} \mathrm{~B}_{1}^{\mathrm{T}} \mathrm{X}+\mathrm{B}_{2} \mathrm{~F}+\mathrm{ZLC}_{2}
$$

The robust $\mathrm{H}_{\infty}$ controller presented in the preceding section is designed for the VSC-HVDC system to maintain the DC bus voltages and large signal operating conditions. This controller, however may not be able to provide the required damping to the electromechanical oscillations of the generator and therefore an auxiliary control derived from the line active power flows to the converter buses is added to $\mathrm{H}_{\infty}$ control output. The auxiliary control unit known as POD (power oscillation damping) controller is designed using either speed or active power error and linear $\mathrm{H}_{\infty}$ control theory. In this study, the damping controller is designed taking the speed error. The error variables are defined by:

$$
\mathrm{e}=\omega_{1}^{\mathrm{ref}}-\omega_{1}
$$

From the above, the error dynamics are given by:

$$
\ddot{\mathrm{e}}+\mathrm{K}_{11} \ddot{\mathrm{e}}+\mathrm{K}_{12} \mathrm{e}=0
$$

The gain parameters are given by $\mathrm{K}_{11}, \mathrm{~K}_{12}$ are determined by placing desired poles on the left-half splane. To satisfy the error dynamics given in Eq. 32, the control quantities $\zeta_{1}$ is found as:

$$
\left[\begin{array}{l}
\dot{\mathrm{e}} \\
\ddot{\mathrm{e}}
\end{array}\right]=\left[\begin{array}{cc}
0 & 1 \\
-\mathrm{K}_{12} & -\mathrm{K}_{11}
\end{array}\right]\left[\begin{array}{l}
\mathrm{e} \\
\dot{\mathrm{e}}
\end{array}\right]+\left[\begin{array}{l}
0 \\
1
\end{array}\right] \zeta_{1}
$$

and

$$
\zeta_{1}=-\frac{1}{\rho} \mathrm{B}^{\mathrm{T}} \mathrm{P}_{\mathrm{r}} \varepsilon
$$

Where, $\rho$ is a weighting factor and $\mathrm{P}_{\mathrm{r}}$ is the solution of the simplified Riccati-like equation:

$$
\mathrm{P}_{\mathrm{r}} \mathrm{A}+\mathrm{A}^{\mathrm{T}} \mathrm{P}_{\mathrm{r}}=-2 \mathrm{Q}
$$

Where matrices Aand B are obtained from Eq. 33 as:

$$
\mathrm{A}=\left[\begin{array}{cc}
0 & 1 \\
-\mathrm{K}_{12} & -\mathrm{K}_{11}
\end{array}\right], \mathrm{B}=\left[\begin{array}{l}
0 \\
1
\end{array}\right]
$$

The gains $K_{11}$ and $K_{12}$ are initially chosen from arbitrary set of poles $\lambda_{1}$ and $\lambda_{2}$.

$$
\mathrm{K}_{11}=\lambda_{1}+\lambda_{2}, \mathrm{~K}_{12}=\lambda_{1} \lambda_{2}
$$

\section{RESULTS AND DISCUSSION}

Steady state stability analysis: To validate the design of the proposed $\mathrm{H}_{\infty}$ controller, the test system shown in Fig. 1a is considered. The system data for simulation 
Int. J. Elec. Power Eng., 4 (3): 182-192, 2010
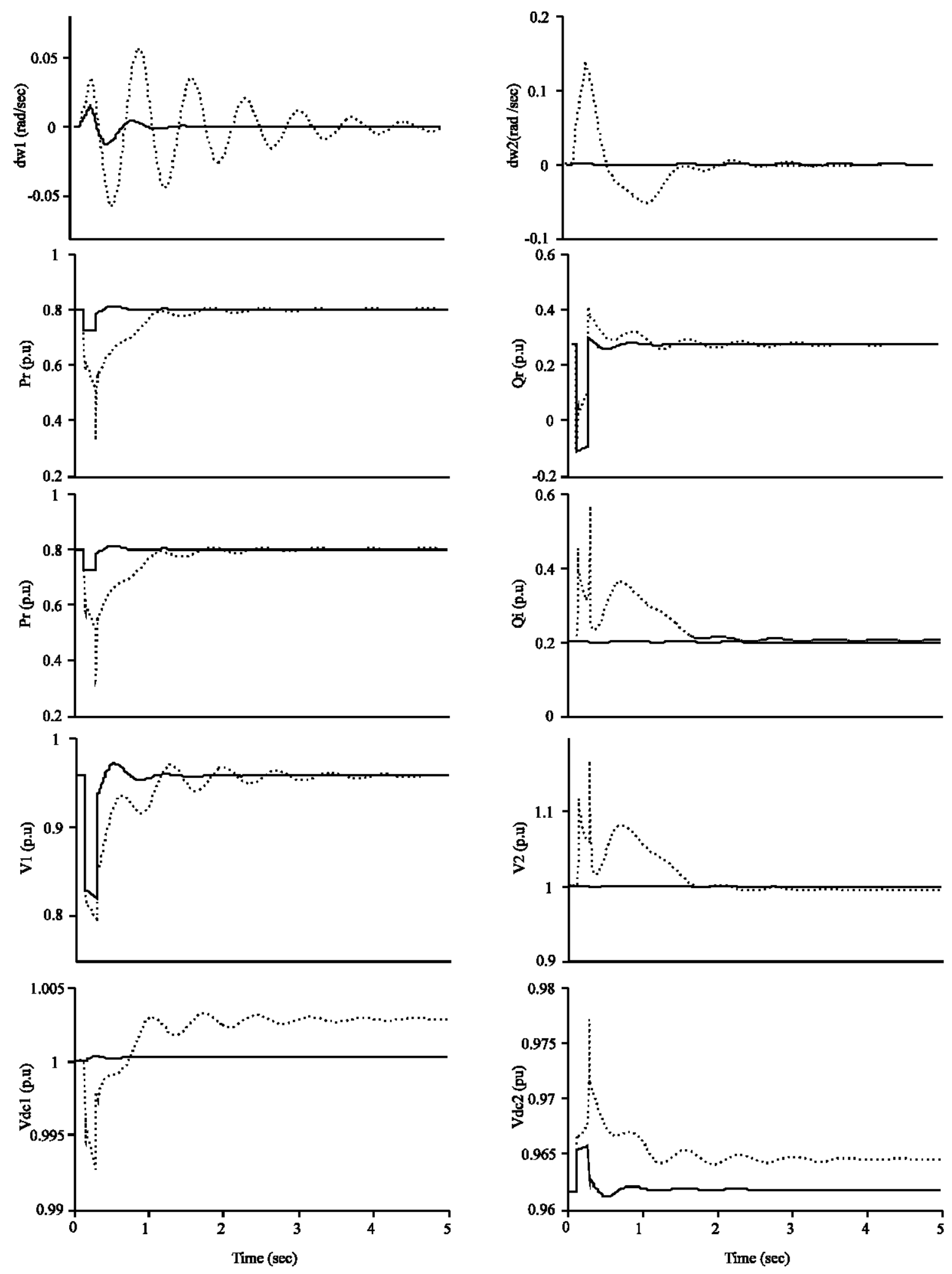

Fig. 4: Performance comparison of the system under LLLG fault at converter bus. Solid line : $\mathrm{H}_{\infty}$ Controller and dashed line: $\mathrm{PI}$ controller, $\mathrm{Pr}=0.8$ and $\mathrm{Qr}=0.272 \mathrm{pu}$ 
studies is given in the Appendix on a $132 \mathrm{kV}, 600 \mathrm{MVA}$ base (AC side) and $150 \mathrm{kV}$ base on the $\mathrm{DC}$ side. The initial operating condition is chosen as $\mathrm{P}_{\mathrm{e} 1}=0.9 \mathrm{pu}, \mathrm{Q}_{\mathrm{el}}=0.3 \mathrm{pu}$ and $\mathrm{P}_{\mathrm{r}}=0.4 \mathrm{pu}, \mathrm{P}_{\mathrm{r}}=0.1 \mathrm{pu}, \mathrm{P}_{\mathrm{e} 2}=0.9 \mathrm{pu}, \mathrm{Q}_{\mathrm{e} 2}=0.3 \mathrm{pu}$ and $\mathrm{P}_{\mathrm{i}}=0.4 \mathrm{pu}, \mathrm{Q}_{\mathrm{i}}=0.1 \mathrm{pu}$.

The VSC HVDC transmission links thus transmits 240 MW power to the inverter side. For this operating condition, from the singular value plot shown in Fig. 3a and $b$, it is observed that the systems' gain and phase margins improve appreciably that ensures the robustness of the system stability with the application of $\mathrm{H}_{\infty}$ controller.

The dotted line represents the singular value of the plant only and the solid lines represent the singular values of the plant after the augmentation of the $\mathrm{H}_{\infty}$ controller derived using the hinfsyn command in the MATLAB.
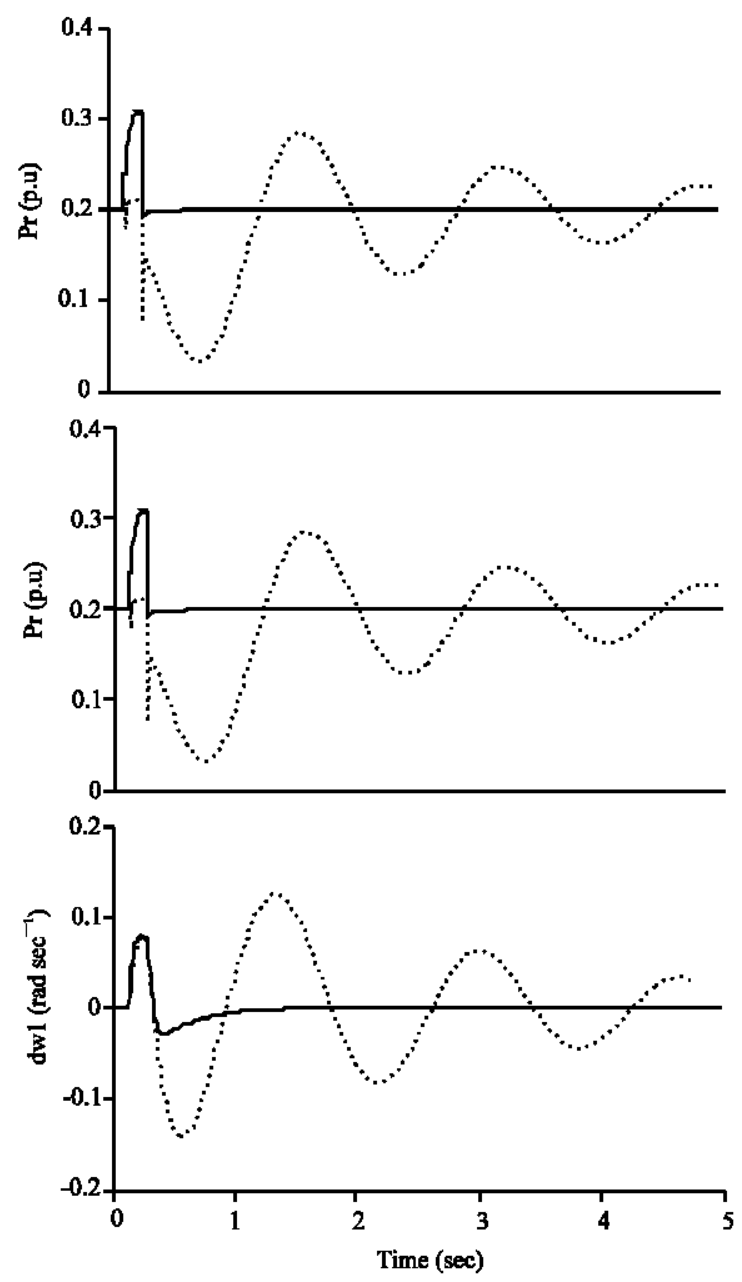

Transient stability analysis of decoupled system

Case 1: Three phase short circuit at the converter bus:

To test the robustness of the designed controller for the HVDC light transmission link, the operating condition of the system is $\mathrm{P}_{\mathrm{r}}=0.8 \mathrm{pu}, \mathrm{Q}_{\mathrm{r}}=0.272 \mathrm{pu}, \mathrm{P}_{\mathrm{i}}=0.71 \mathrm{pu}, \mathrm{Q}_{\mathrm{i}}=$ $0.2 \mathrm{pu}$. Figure 4 shows the transient response for a 10 cycle 3-phase to ground fault.

From the Fig. 4, it is evident that the oscillations in the speeds of the generators and the interarea oscillations are damped out faster with the new control than the conventional PI controller.

Due to $\mathrm{H}_{\infty}$ control for the reactive power control loop at the rectifier station, the voltage of the converter $\mathrm{AC}$ bus recovers much faster. Further, the fault at the converter bus hardly affects the power flow to the converter bus. The DC-bus voltages are stabilized very well using this control.
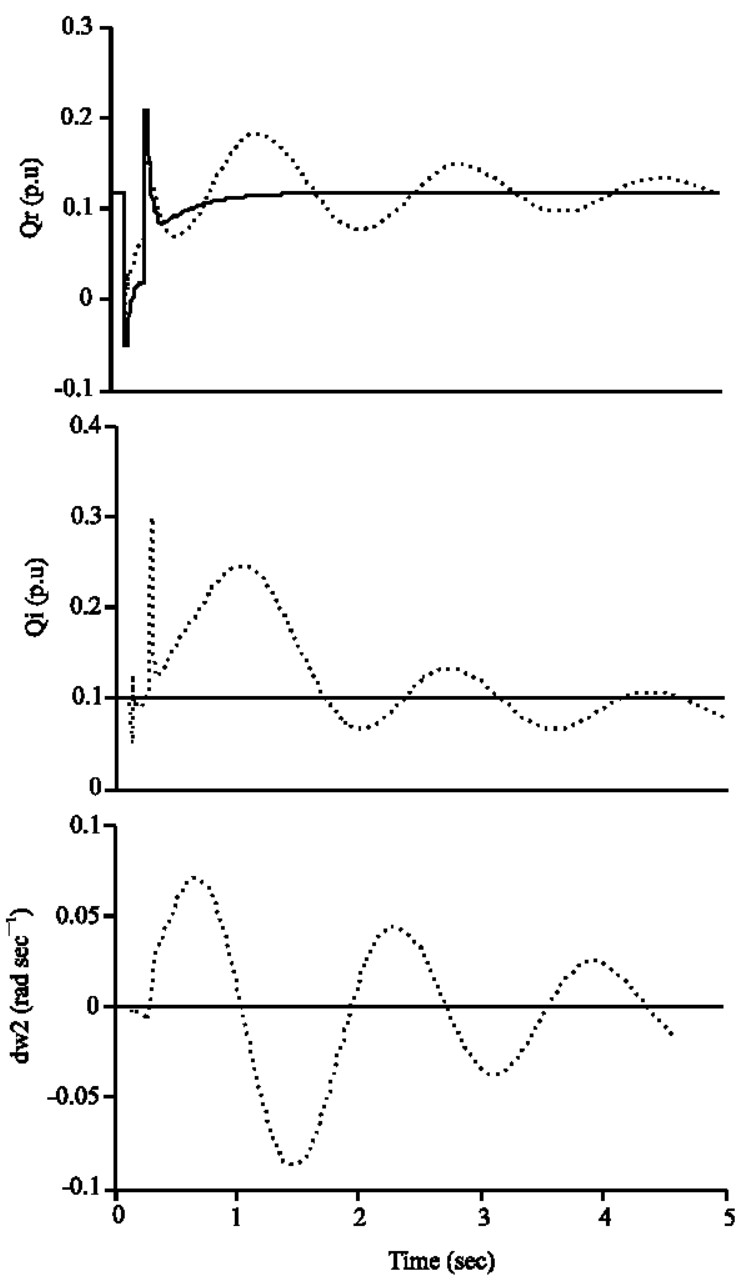

Fig. 5: Performance comparison of the system under LLLG fault at converter bus. Solid line: $\mathrm{H}_{\infty}$ controller and dashed line: $\mathrm{PI}$ controller, $\mathrm{Pr}=0.2 \mathrm{pu}$ and $\mathrm{Qr}=0.12 \mathrm{pu}$ 
To simulate a light loading condition of the generator on the rectifier side the operating point is chosen as $\mathrm{P}_{\mathrm{r}}=0.2 \mathrm{pu}, \mathrm{Q}_{\mathrm{r}}=0.12 \mathrm{pu}, \mathrm{P}_{\mathrm{i}}=0.18586 \mathrm{pu}, \mathrm{Q}_{\mathrm{i}}=0.1 \mathrm{pu}$ and $\mathrm{a}$ similar three-phase fault is initiated at the bus 1 and cleared after 10 cycles. The system dynamic response is shown in Fig. 5 which confirms the superiority of the new controller in damping out electromechanical oscillations of the generators while maintaining $\mathrm{AC}$ and $\mathrm{DC}$ side voltages constant. Besides, the converter and inverter power flows are maintained, damping out any oscillation in them.

In this case, a three-phase to ground fault is simulated at converter bus which affects the performance of the HVDC light. The operating point chosen here is $P_{r}=-0.2 \mathrm{pu}, \mathrm{Q}_{\mathrm{r}}=-0.1 \mathrm{pu}, \mathrm{P}_{\mathrm{i}}=-0.205 \mathrm{pu}, \mathrm{Q}_{\mathrm{i}}=-0.05 \mathrm{pu}$. The effectiveness of the robust controller is tested here which gives much more satisfactory result in comparison to the
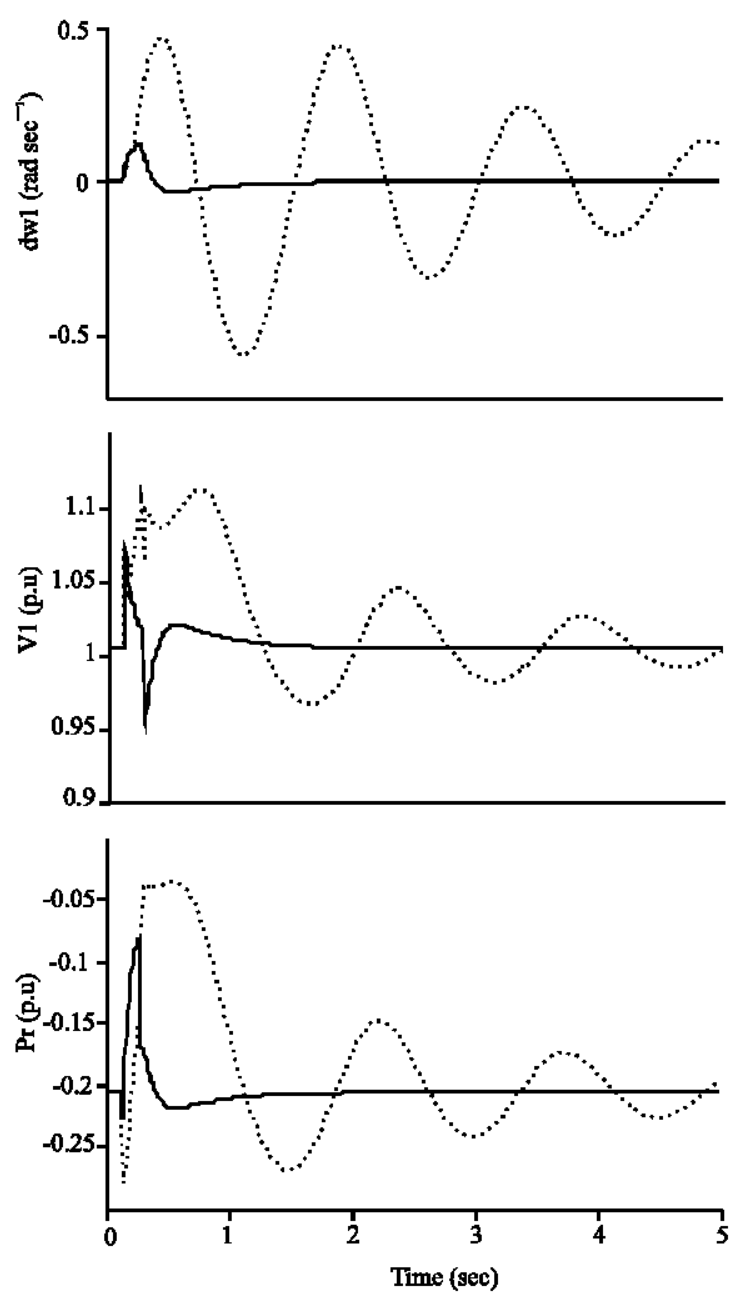

PI controller during this fault as shown in Fig. 6. The fault duration is 10 cycles as used in the preceding simulations. The controller stabilizes the system faster in comparison to the PI controller.

Case 2: Three phase short circuit at the inverter bus: In this case, a three-phase to ground fault is simulated at bus two (inverter bus) which affects the performance of the HVDC light. The operating point chosen here is $\mathrm{P}_{\mathrm{r}}=-0.2 \mathrm{pu}, \mathrm{Q}_{\mathrm{r}}=-0.1 \mathrm{pu}, \mathrm{P}_{\mathrm{i}}=-0.205 \mathrm{pu}, \mathrm{Q}_{\mathrm{i}}=-0.05 \mathrm{pu}$. The effectiveness of the robust controller is tested here which gives much more satisfactory result in comparison to the PI controller during this fault as shown in Fig. 7.

The fault duration is 10 cycles as used in the preceding simulations. The controller stabilizes the system faster in comparison to the PI controller. Further, the PI controller which performed some what
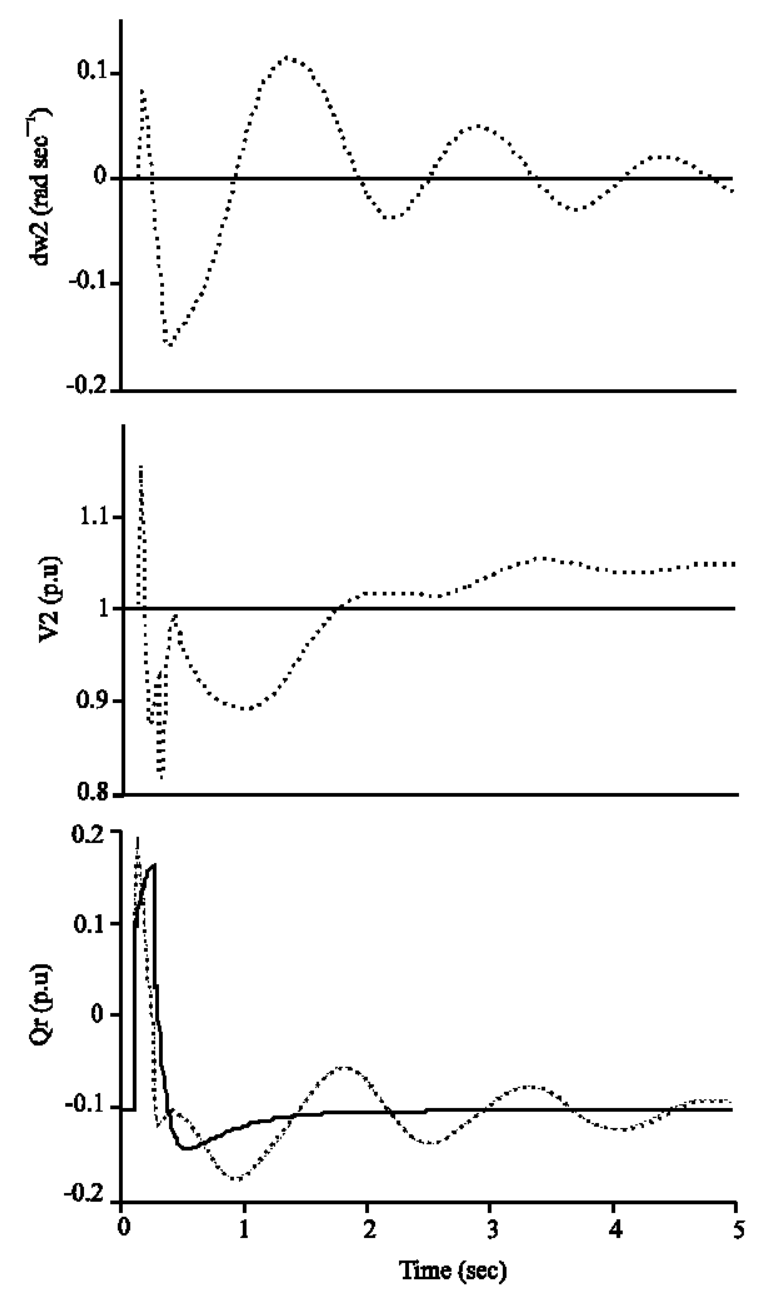

Fig. 6: Performance comparison of the system under LLLG fault at converter bus. Solid line: $\mathrm{H}_{\infty}$ controller and dashed line: the PI controller, $\mathrm{Pr}=-0.2 \mathrm{pu}$ and $\mathrm{Qr}=-0.1 \mathrm{pu}$ 
Int. J. Elec. Power Eng., 4 (3): 182-192, 2010
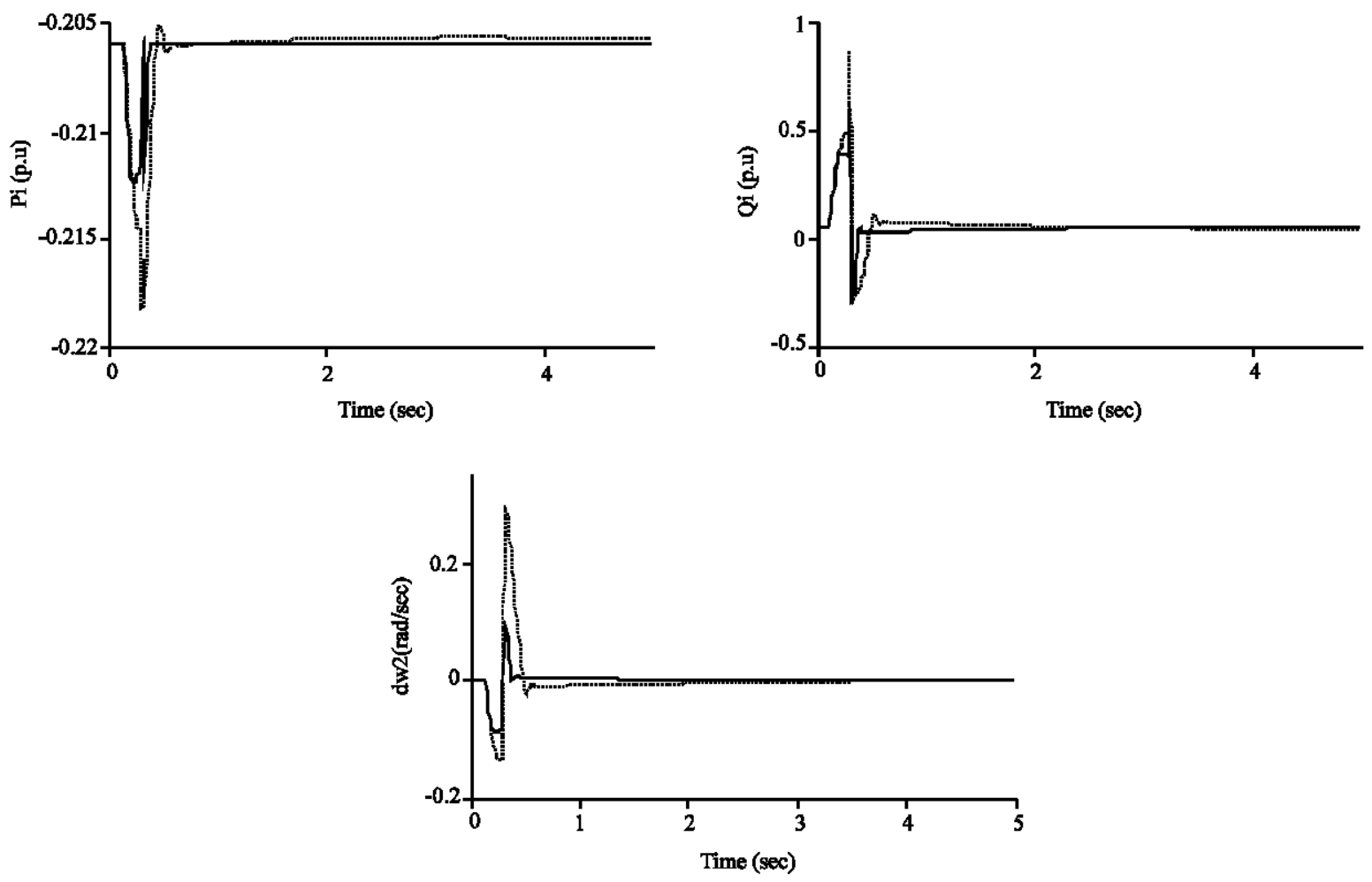

Fig. 7: Performance comparison of the system under LLLG fault at Inverter bus. Solid line: $\mathrm{H}_{\infty}$ controller and dashed line: PI controller, $\mathrm{Pr}=-0.2 \mathrm{pu}$ and $\mathrm{Qr}=-0.1 \mathrm{pu}$
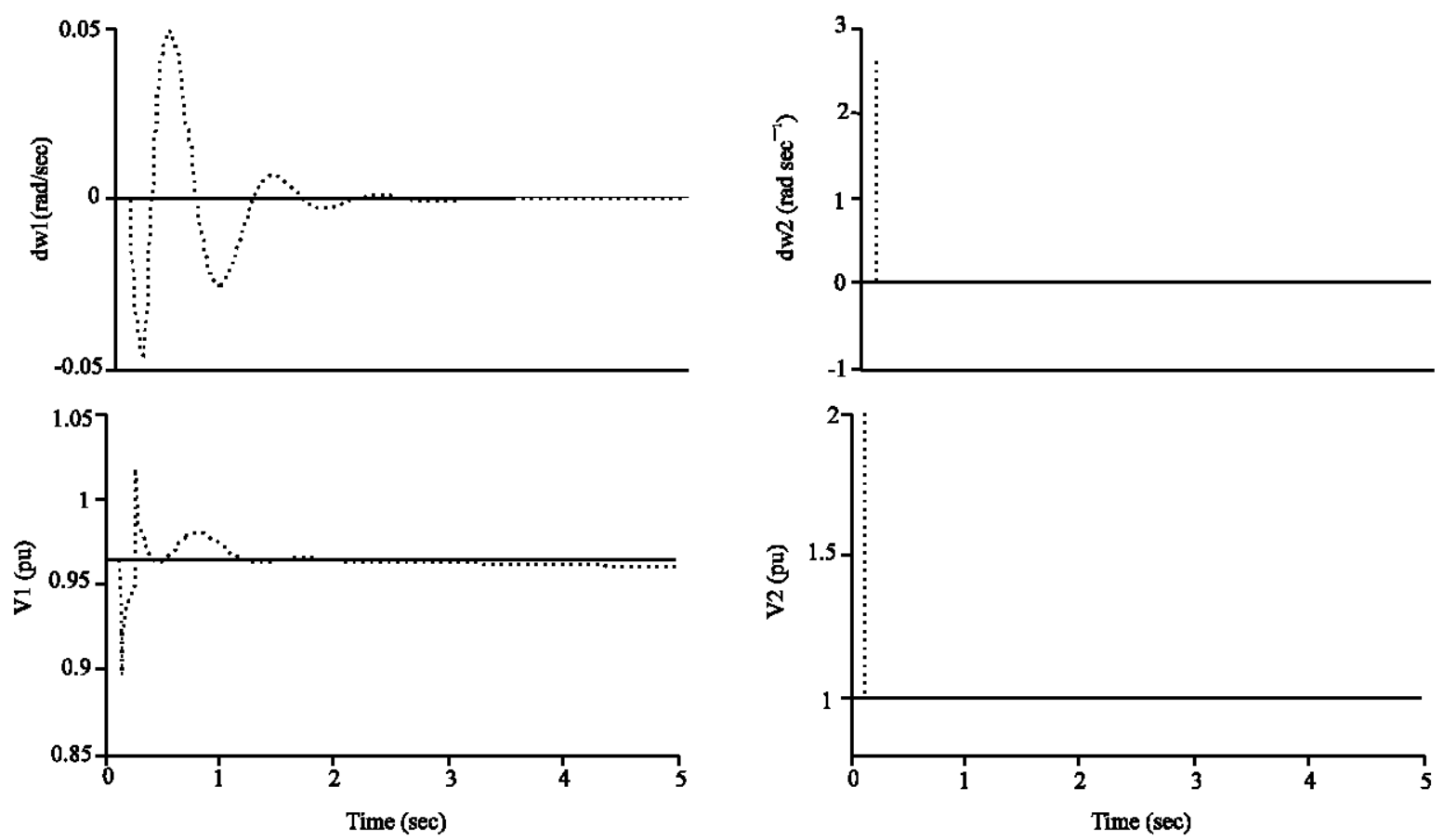

Fig. 8: Continued 

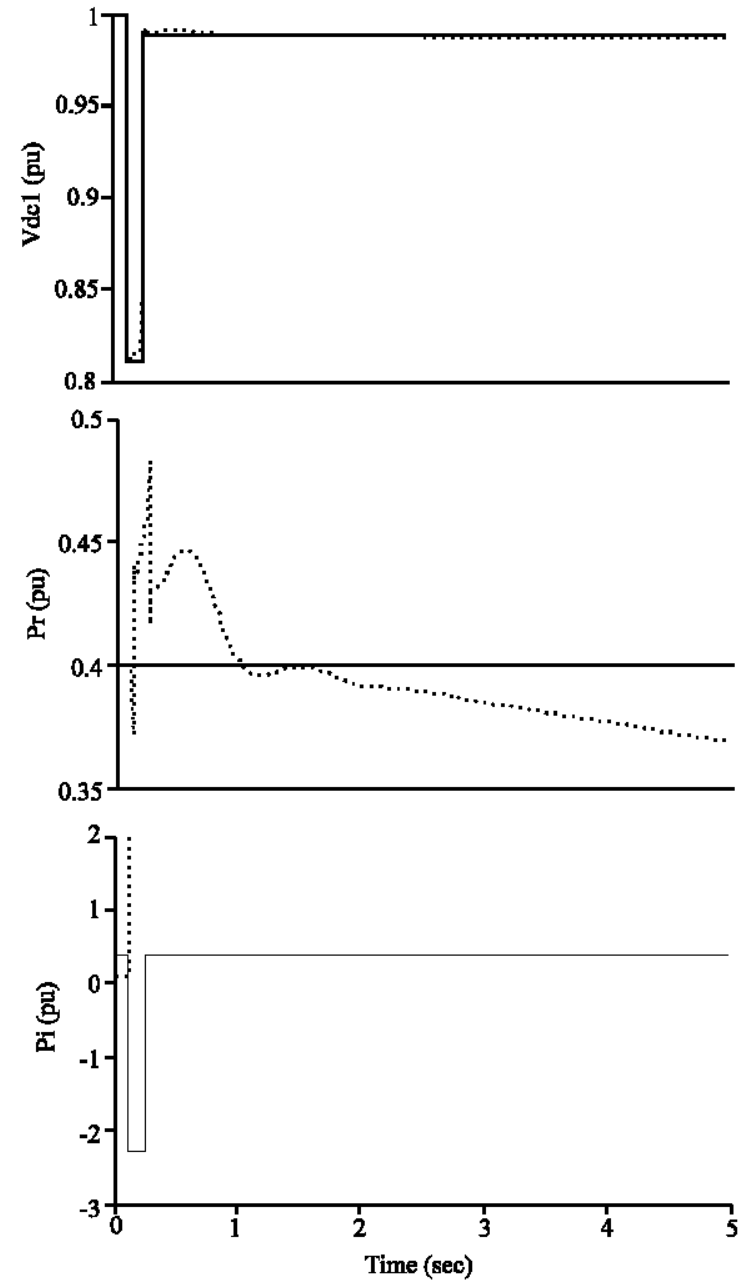
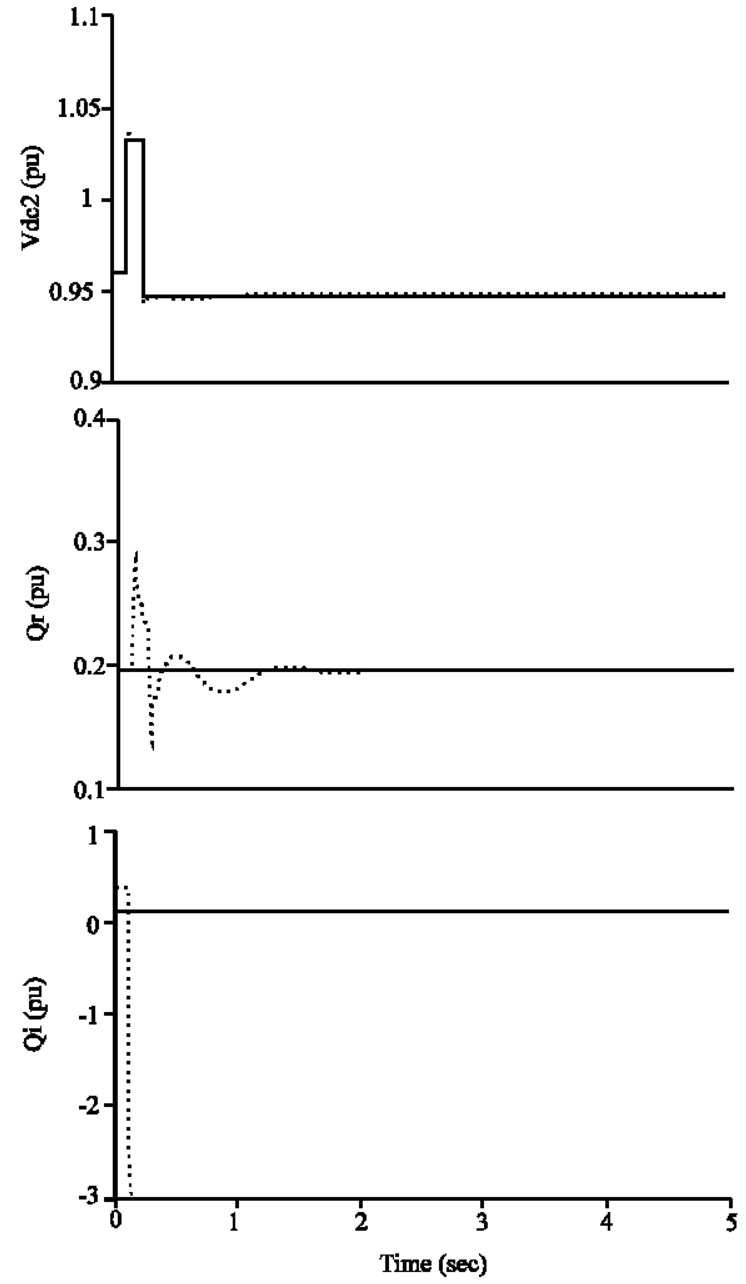

Fig. 8: Performance comparison of the system under LG fault at DC bus. Solid line: $\mathrm{H}_{\infty}$ controller and dashed line: PI controller, $\mathrm{Pr}=0.4 \mathrm{pu}$ and $\mathrm{Qr}=0.2 \mathrm{pu}$

better for earlier operating points could not stabilize the converter active and reactive power oscillations and also resulted in overshoots in the speed oscillations of the generators.

Case 3: Line to ground fault at DC bus: To study the robustness of the proposed controller, a DC line to ground fault was initiated near the converter DC bus and cleared in 10 cycles.

The DC bus voltage, active and reactive powers of the converters and the inter-area oscillations are shown in Fig. 8.

From the Fig. 8, it is evident that the performance of the HVDC Light system is very robust and practically the excursions in the various states are absolutely minimal, where as the performance of the conventional controller is worst showing oscillations and steady state error. The operating condition chosen for the simulation of $\mathrm{DC}$ fault is $P_{r}=0.4 p u, Q_{r}=0.2 p u, P_{i}=0.37 p u, Q_{i}=0.1 p u$ overshoots in the speed oscillations of the generators.

\section{CONCLUSION}

The proposed controller is eveluated in this study and its performance shows better results than the earlier used PI controllers in respect of the reduction of overshoots, faster settling times and improved damping for the electromechanical oscillations of the generators.

\section{APPENDIX}

Generator:

$$
\frac{\mathrm{d} \delta_{\mathrm{k}}}{\mathrm{dt}}=\omega_{\mathrm{k}}-\omega_{\mathrm{k} 0}
$$




$$
\frac{\mathrm{d} \omega_{\mathrm{k}}}{\mathrm{dt}}=\frac{\left(\mathrm{Pm}_{\mathrm{k}}-\mathrm{Pe}_{\mathrm{k}}\right)}{\mathrm{IC}_{\mathrm{k}}}
$$

Where:

$$
\begin{gathered}
\mathrm{IC}_{\mathrm{k}}=\frac{\mathrm{H}_{\mathrm{k}}}{2 \pi} \\
\frac{\mathrm{dE}_{\mathrm{qk}}^{\prime}}{\mathrm{dt}}=\frac{1}{\mathrm{~T}_{\mathrm{dk}}^{\prime}}\left(\Delta \mathrm{E}_{\mathrm{fdk}}+\mathrm{E}_{\mathrm{fdk}}-\mathrm{E}_{\mathrm{qk}}^{\prime}-\left(\mathrm{x}_{\mathrm{dk}}-\mathrm{x}_{\mathrm{ddk}}\right) \mathrm{I}_{\mathrm{kd}}\right) \\
\frac{\mathrm{d} \Delta \mathrm{E}_{\mathrm{fk}}^{\prime}}{\mathrm{dt}}=-\mathrm{K}_{\mathrm{ek}} \Delta \mathrm{E}_{\mathrm{fk}}^{\prime}+\frac{\mathrm{K}_{\mathrm{ek}}}{\mathrm{T}_{\mathrm{e} 1}}\left(\mathrm{~V}_{\mathrm{tkref}}-\mathrm{V}_{\mathrm{tk}}\right)
\end{gathered}
$$

for $\mathrm{k}=1,2$.

The specification of the system studied is as follows. Base MVA: 600, Base kV = 132 (AC) and 150 (DC).

Generator 1: $\mathrm{X}_{\mathrm{d} 1}=1.8, \mathrm{X}_{\mathrm{q} 1}=1.7, \mathrm{X}_{\mathrm{d} 1}=0.3, \mathrm{X}_{\mathrm{q} 1}=0.55$, $\mathrm{H}_{1}=6.5$.

Generator 2: $\mathrm{X}_{\mathrm{d} 2}=1.8, \mathrm{X}_{\mathrm{q} 2}=1.7, \mathrm{X}_{\mathrm{d} 2}=0.19, \mathrm{X}_{\mathrm{q} 2}=0.55$, $\mathrm{H}_{2}=5.5$.

Transmission line: AC Line $-1, x_{t 11}=x_{t 12} 0.05 \Omega \mathrm{km}^{-1}(25$ $\mathrm{km})$; AC Line $-2, \mathrm{x}_{\mathrm{t} 21}=\mathrm{x}_{\mathrm{t} 22}=0.05 \Omega \mathrm{km}^{-1}(25 \mathrm{~km})$. AC parallel line, $\mathrm{x}_{12}{ }^{1}=\mathrm{x}_{12}{ }^{2}=0.05 \Omega \mathrm{km}^{-1}(150 \mathrm{~km}) ; \mathrm{DC}$ transmission line resistance $\mathrm{R}_{\mathrm{dc}}=0.01 \Omega \mathrm{km}^{-1}(150 \mathrm{~km})$.

Converter station: $\mathrm{r}_{\mathrm{r}}=1.452 \Omega, \mathrm{r}_{\mathrm{i}}=1.452 \Omega, \mathrm{x}_{\mathrm{r}}=2.9 \Omega$, $\mathrm{x}_{\mathrm{i}}=2.9 \Omega ; \mathrm{C}_{\mathrm{dc}}=5000 \mu \mathrm{F}$. Switching Frequency: $\mathrm{f}_{\mathrm{s}}=2 \mathrm{kHz}$. AC Filters: $\mathrm{C}=9.16 \mu \mathrm{F}$.

PI controller gains: Rectifier side ( reactive power and dc voltage error used as control signals): $\mathrm{K}_{\mathrm{p} 1}=3.5, \mathrm{~K}_{\mathrm{i} 1}=0.1$, $\mathrm{K}_{\mathrm{p} 2}=2.0, \mathrm{~K}_{\mathrm{i} 2}=0.3$; Inverter side (for active and reactive power errors used for control signals): $\mathrm{K}_{\mathrm{p} 3}=-4.0, \mathrm{~K}_{\mathrm{i} 3}=0.2$, $\mathrm{K}_{\mathrm{p} 4}=-4.0, \mathrm{~K}_{\mathrm{i} 4}=-0.2$.

\section{H-infity control gains:}

$\mathrm{K}_{11}=0.2, \mathrm{~K}_{12}=0.15, \mathrm{~K}_{22}=0.35, \mathrm{~K}_{24}=0.8, \mathrm{~K}_{34}=0.28, \mathrm{~K}_{35}=$ $-0.2, \mathrm{~K}_{44}=0.15, \mathrm{~K}_{45}=-0.3$. All other elements of the $4 \times 5 \mathrm{~K}$ matrix are zeroes.

\section{REFERENCES}

Andersen, B.R., L. Xu, P.J. Horton and P. Cartwright, 2002. Topologies for VSC transmission. Power Eng. J., 16: 142-150.

Asplund, G., 2000. Application of HVDC light to power system enhancement. IEEE Power Eng. Soc. Winter Meeting, 4: 2498-2503.

Durrant, M., H. Werner and K. Abbott, 2004. Synthesis of multi-objective controllers for a VSC HVDC terminal using LMIs. IEEE Conf. Decision Control, 4: 4473-4478.

Jowder, F.A.R. and B.T. Ooi, 2004. VSC-HVDC station with SSSC characteristics. IEEE Trans. Power Electronics, 19: 1053-1059.

Liang, H., G. Li, G. Li, P. Li and M. Yin, 2005. Analysis and design of $\mathrm{H} 8$ Controller in VSC HVDC systems. IEEE/PES Trans. Distribut. Conf. Exhibition: Asia Pacific, pp:1-6. 10.1109/TDC.2005.1547069

Lignon, S., J.J. Sinou and L. Jezequel, 2006. Stability analysis and mu-synthesis control of brake systems. J. Sound Vibration, 298: 1073-1087.

Pal, B.C., 2002. Robust damping of interarea oscillations with unified power flow controller. IEE Proc. Gen. Transmission Distrib., 149: 733-738.

Ruan, S. Y., G.J. Li, L. Peng, Y.Z. Sun and T.T. Lie, 2007a. A nonlinear control for enhancing HVDC light transmission system stability. Electric Power Energy Syst., 29: 565-570.

Ruan, S.Y., G.J. Li, X.H. Jiao, Y.Z. Sun and T.T. Lie, $2007 \mathrm{~b}$. Adaptive control design for VSC-HVDC system based on backstepping approach. Electric Power Syst. Res., 77: 559-565.

Zhang, G. and Z. Xu, 2001. Steady-state model for VSC based HVDC system and its controller design. IEEE Power Eng. Soc. Winter Meeting, 3: 1085-1090.

Zhang, G.B., X. Zheng and W. Guang zhu, 2002. Steady state model and its nonlinear control of VSC-HVDC system. Proc. CSEE, 22: 17-22. 